\title{
DERMATOGLYPHICS AND INTELLIGENCE QUOTIENT (IQ) IN CHILDREN OF THE AGE GROUP 4 TO 7 YEARS IN THE SOUTH INDIAN POPULATION
}

\author{
Madhumitha Prabhakaran', Sudakshina Chakrabarti2, Gunapriya Ragunath ${ }^{3}$ \\ 1 Final Year MBBS Student, Saveetha Medical College and Hospital, Chennai, Tamilnadu, India. \\ ${ }^{2}$ Assistant Professor, Department of Anatomy, Saveetha Medical College and Hospital, Tamilnadu, India. \\ ${ }_{3}^{3} \mathrm{HOD}$, Department of Anatomy, Saveetha Medical College and Hospital, Tamilnadu, India.
}

\begin{tabular}{l}
\hline ABSTRACT \\
BACKGROUND \\
Dermatoglyphics is considered to be a window to a child's personal characteristics and a sensitive indicator of brain function \\
abnormalities. Widespread interest in epidermal ridges is developing in the medical field. In this study, certain specific patterns \\
were prominent in high, intermediate and low IQ groups which were characteristic of these groups.
\end{tabular}

\section{METHODS}

This cross-sectional study was conducted on 1000 school going children in the South Indian population. Hand prints were taken using the lipstick method. A modified version of the Wechsler Pre-School and Primary Scale of Intelligence was used to assess the intelligence of the students and they were accordingly grouped into high, intermediate, and low intelligence quotient groups. The hand prints from each of the intelligence groups were analysed thoroughly using standard parameters such as fingertip pattern, finger ridge count, palmar ridge count, and palmar angles. The results were tabulated and interpreted.

\section{RESULTS}

High intelligence levels showed the highest proportion of loops in all their digits. As the intelligence level decreased, the incidence of the arches and whorls increased. The thumb and $1^{\text {st }}$ digit especially showed these variations. The $4^{\text {th }}$ digit shows the highest incidence of loops in the high intelligence group with a number of 468 , that is, $80.7 \%$ of loops. When taking the 1 st digit into consideration, the high intelligence quotient group showed $61.4 \%$ of loops, while the intermediate level shows just $54.5 \%$ of loops. The $1^{\text {st }}$ digit of the low intelligence level is the only one in the entire study to show more number of whorls than loops. Nearly half the patterns, that is $47.9 \%$, were whorls in the low IQ group. The thumb also showed a higher number of whorl patterns and arch patterns with $36.6 \%$ and $20.6 \%$ respectively in low IQ group. In the low IQ level group, there is a significant difference between the total and absolute finger ridge count, indicating a greater prominence of whorl patterns. As the intelligence decreases, the difference between the total and absolute finger ridge counts increases, which correlates with the increase in the incidence of whorls. And finally, we found that the A-B ridge count increases as the intelligence decreases.

\section{CONCLUSIONS}

This study thus attempts to determine certain dermatoglyphic patterns in children of 4 to 7 years of age of varying intelligence quotient which may be extremely helpful in future studies by proving a basal patterning. It calls for further studies in the future to establish a definite relationship between intelligence and observed patterns.

HOW TO CITE THIS ARTICLE: Prabhakaran M, Chakrabarti S, Ragunath G. Dermatoglyphics and intelligence quotient (IQ) in children of the age group 4 to 7 years in the South Indian population. J. Evolution Med. Dent. Sci. 2019;8(14):1178-1187, DOI: $10.14260 /$ jemds $/ 2019 / 261$

\section{BACKGROUND}

The term 'dermatoglyphics' was coined by Dr. Harold Cummins, the father of American fingerprint analysis. The word comes from two Greek words: 'derma' meaning skin and 'glyphe' meaning to carve. It refers to the friction ridge formations which appear on the palms of the hands and soles of the feet during intrauterine life.

Dr. Cummins first established the direct relationship between the patterns of formation of ridges on the palm and the development of the brain in the year 1926.

'Financial or Other Competing Interest': None.

Submission 12-02-2019, Peer Review 21-03-2019,

Acceptance 28-03-2019, Published 08-04-2019.

Corresponding Author:

Dr. Sudakshina Chakrabarti,

Assistant Professor,

Department of Anatomy,

Saveetha Medical College and Hospital,

Tamilnadu, India.

E-mail: subhianat@gmail.com

DOI: $10.14260 /$ jemds $/ 2019 / 261$

\section{(c) $(1)(-$}

In the nineteenth century, British eugenicist Sir Francis Galton, had collected many human fingerprints and identified various lines of statistical frequency. He was the first person who proposed that there is a connection between human prints and genetics. In the 1930s, U.S. scholars began to use prints to identify whether a newborn has down syndrome and other potential mental illnesses. Recently, foreign scholars claim that they understand enough of human prints to judge the potential of human brain.[1] Ever since, Dermatoglyphics has wide usage in diagnosis and behaviour analysis of people with schizophrenia, mental retardation, and many such diseases including heart diseases.

Western scientists believe that dermatoglyphics is the DNA genes of the human body that are reflected in appearance. Although everyone has different prints, they can be categorized into distinctive categories. Skin begins to develop on the embryo in the 13th week of life, and it is completely formed in the 19th week. Therefore, it is closely related to the infant's brain development which occurs at the same time. The distribution of prints is considered to represent brain cells' proportion and distribution in each of the brain lobes. Medical experts and scientists believe that 
the amount of brain cells distributed in different parts of the brain help us understand a person's multiple intelligence as well as his innate potential capabilities and personality. Parents can understand their children/ babies' innate character and learning potential. European and American experts found that fingerprints show different kinds of characteristics, even with monozygotic (identical) twins. Interestingly enough, the same fingerprints will appear again after healing of wound, as long as the injury has not affected the cells. [2]

The history of intelligence quotient started in 1904 when a man named Alfred Binet lived in France and noticed that many children in school were struggling, but he didn't think it was due to lack of intelligence. He said that some children will do badly because they simply aren't intelligent, so there's not much that can be done to directly help them improve their grades. However, he said that other children have plenty of learning ability and potential to do well, but they struggle simply because of life circumstances. He said that these children, who have a high learning ability, should be distinguished from children who do badly in school because of low intelligence.

This distinction is what paved the way for Binet's new idea, which he called the intelligence quotient, or IQ for short. Everyone has an individual intelligence quotient, which is a number indicating your inherent ability to learn instead of simply the knowledge you already have. If you have a high IQ, it means that you have the intelligence required to do well in school because you have the ability or potential to succeed.[3]

A recent advancement in the field of dermatoglyphics and intelligence quotient has emerged called the DMIT. Dermatoglyphics Multiple Intelligence test is a truly scientific study of the fingerprint patterns. This will help in understanding a great individual's potential \& personality Type. Dermatoglyphics Multiple Intelligence Test (DMIT) is based on understanding from Neuroscience, Genetics, Dermatoglyphics, Psychology and Embryology. DMIT Test assessment method has been formulated by scientists and Medical experts. DMIT Test has accepted by the entire world and also from renowned universities. Medical experts and approved clinical experience confirmed that finger prints provide accurate analysis of humans Multiple Intelligences and inborn potential. Traditionally only an IQ test is used to be a measurement tool for degree of intelligence. Now the DMIT is used in the fields of school, college, and educational institutions, human resource management, children memory, enhancements programs, career guidance and career counseling.[4]

\section{Aims and Objectives}

1. To observe the finger print patterns of 1000 school going children in the South Indian population in the age group 4 to 7 years.

2. To observe and analyze prevalent characteristics of dermatoglyphic patterns in children of age group 4 to 7 years.

3. To determine a specific dermatoglyphic pattern for different ranges of intelligence quotient in children of the age group 4 to 7 years.

\section{METHODS}

It is a cross-sectional study conducted at The Pupil Saveetha Eco School located in Chennai, Tamil Nadu on 1000 subjects aged between $4+$ to $7+$ years of age. The research work was initiated on July 2017 and lasted for a total duration of three months. Institutional Ethics Committee (IEC) clearance was obtained before beginning the study. Informed consent forms duly understood and signed from parents were obtained prior to the study. As all parents were literate, they were briefed in a meeting and informed consent was obtained from all of them. Proper oral assent was obtained from the children prior to conductance of the study and no child was forced to participate. As this study involved a fun activity in the form of intriguing questions and hand painting children were very excited to take part in it.

Determination of Intelligence Quotient for children of 4 to 7 years of age was done with the standard scales of Wechsler Pre-School and Primary Scale of Intelligence (WPPSI).[5] A modified version of the test was used for convenience as the study had to be conducted on 1000 students of 4 to 7 years of age in a specified time period. A series of questions were prepared to accurately measure the intelligence levels of the children in pre-kindergarten, kindergarten, $1^{\text {st }}$, and $2^{\text {nd }}$ grade. They were grouped into high, intermediate, and low intelligence levels taking into consideration their marks obtained and current grade they are studying in.

The palm print was taken by the Inkless Method by using lipstick of a dark shade. This 'Lipstick' method requires a dark shade of 'Lip stick', a foam rubber pad and a white sheet of paper. The lipstick was applied on the entire palm of the subject including the digits. Then the sheet of paper was placed on top of the foam rubber pad on a flat, stable surface. The subject's palm was placed on this and gently pressed. The foam pad was used to fill the concavity of the palm when pressure was applied to the back of the hand to prevent blank areas or white spaces from appearing in the center of the palm. Then each digit was gently pressed to make sure it also appeared like the palm print. Both the left and right hand prints were taken in all the subjects. The subject did not need to wash his/her hands as the lipstick's color came off easily by wiping with a soft, damp cloth and left a nice perfume too[6] The subjects were included at random. Students who were sick, non-cooperative, unwell and unwilling to participate on that day were excluded from the study.

Prints were studied using a magnifying lens to identify the finger and palm patterns.

Various patterns of prints will be analyzed according to the standard guidelines for classification of patterns as follows-

1. First the fingertip pattern will be identified as loop, whorl, or arch.

2. In a loop: A line will be drawn from the core to the triradius and the ridges crossing the line will be counted for the finger ridge count.

3. In a whorl: A whorl has two triradii and hence the counting will be done with both triradii. From the core, a line will be drawn to one triradius and in the same manner to other triradius and counting will be done.

4. In an arch: The triradius is the core and hence the finger ridge count is zero.

5. ATD, ADT, DAT angles: A line will be drawn from axial triradius ' $t$ ' to the digital triradii ' $a$ ' and ' $d$ ' and all the 
three angles in the triangle will be measured using a protractor.

6. A-B ridge count: The number of ridges crossing the line drawn from ' $a$ ' to ' $b$ ' will be counted.

7. Total finger ridge count (TFRC) will be recorded by adding the finger ridge counts taking the half count of a whorl, of all ten fingers. (The finger ridge count of only one triradii)

8. Absolute finger ridge count (AFRC) will be recorded by adding the finger ridge counts, of all ten fingers, taking the complete count of a whorl into consideration. [7]

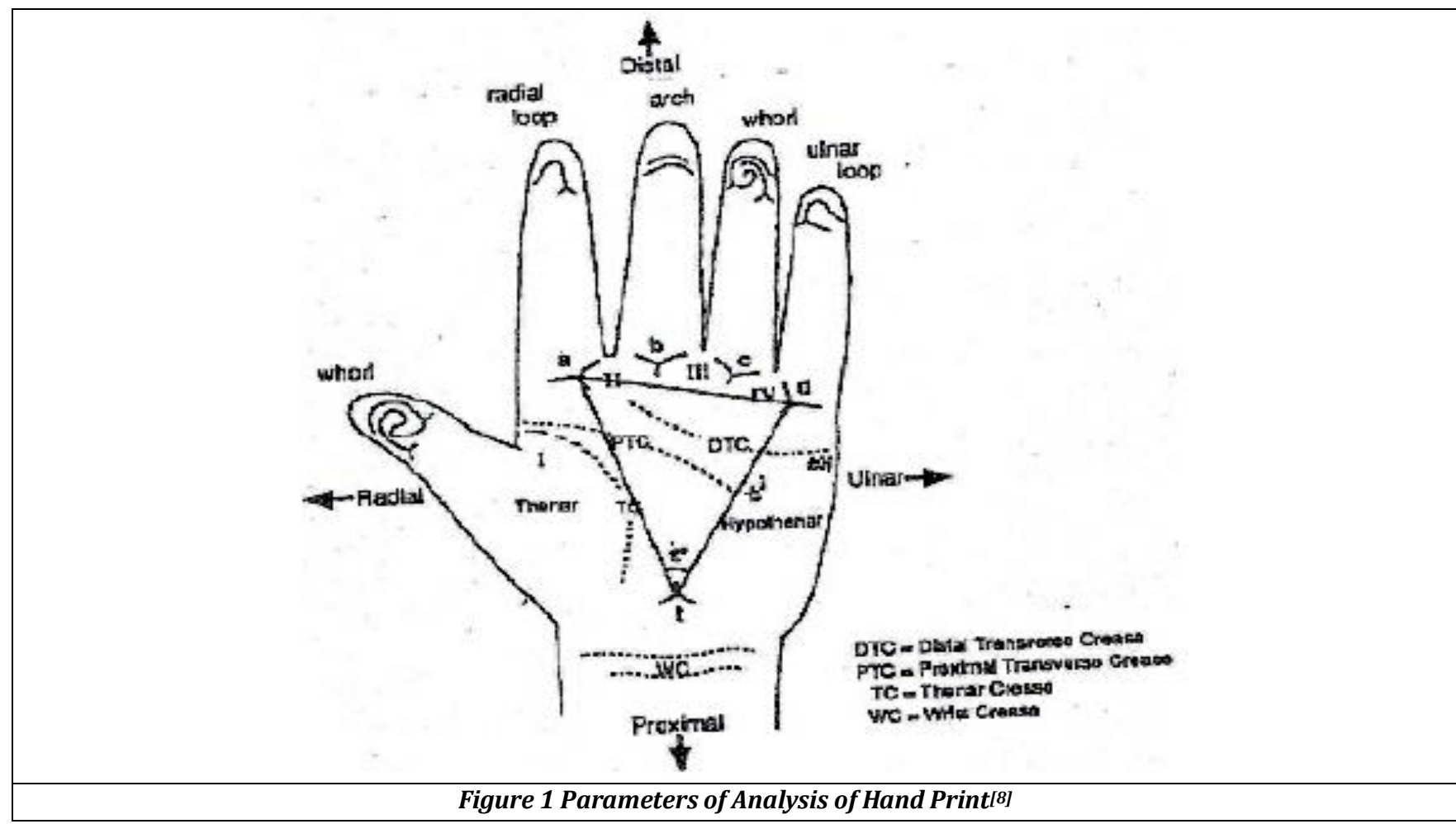

\section{RESULTS}

\section{Pattern of Print on Each Digit}

A total of 1000 students of age group $4+$ to $7+$ years were included in the present study. 290 students were grouped according to their IQ into the high intelligence quotient category, 453 students of the intermediate IQ group, and the remaining 257 were of low IQ group as shown in Table 1. Most of the students belonged in the intermediate IQ group as shown in Chart 1.

\begin{tabular}{|c|c|c|c|}
\hline & High IQ & Intermediate IQ & Low IQ \\
\hline Total Number of Students & 290 & 453 & 257 \\
\hline \multicolumn{2}{|c|}{ Table 1. Total Number of Students Under Each Group } \\
\hline
\end{tabular}

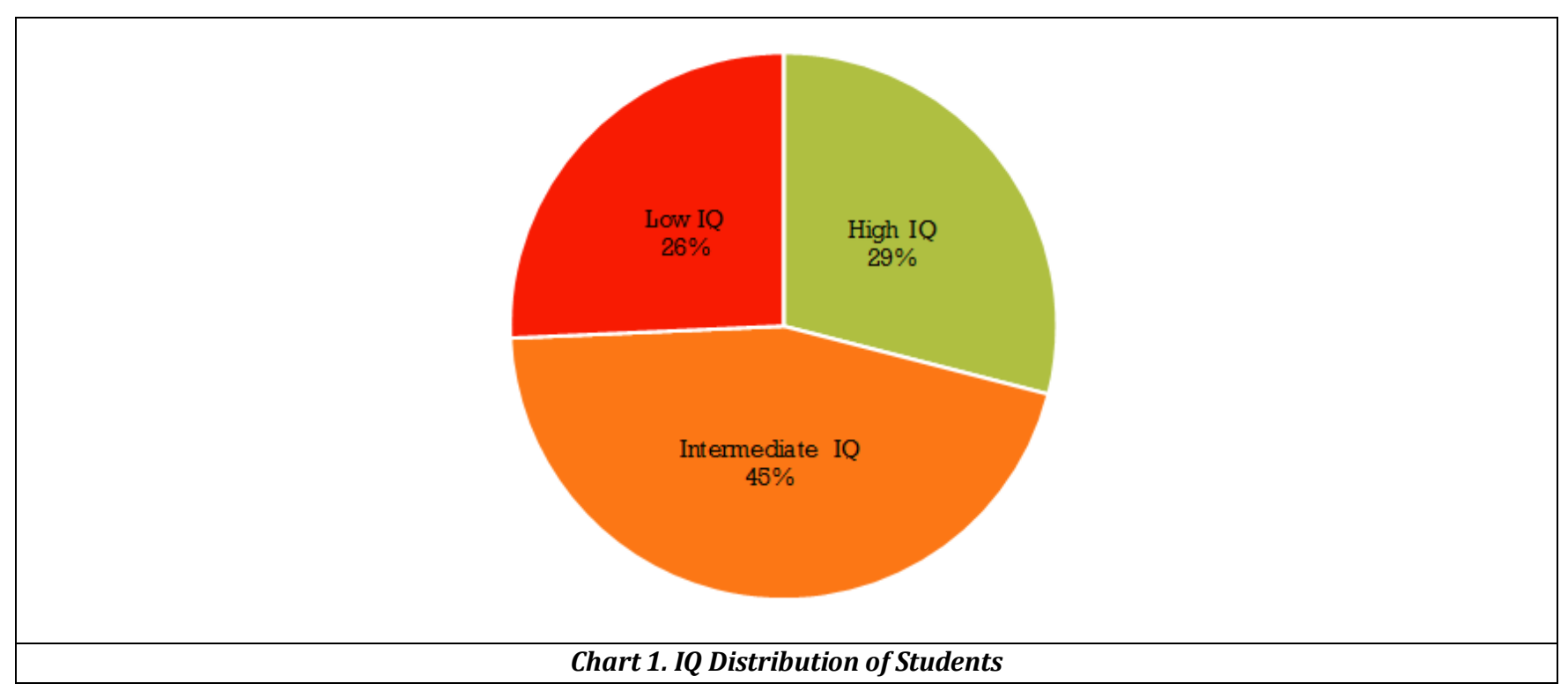


Table 2 shows the distribution of finger print patterns of high intelligence group in all the five digits of both the hands. The loop pattern was the highest and was seen in 384 thumbs, 356 in $1^{\text {st }}$ digit, 450 in $2^{\text {nd }}$ digit, 442 in $3^{\text {rd }}$ digit and 468 in $5^{\text {th }}$ digit. The $4^{\text {th }}$ digit shows the highest incidence of loops with a number of 468 , that is $80.7 \%$ of finger print pattern. The next most common pattern in this high IQ group were whorls. The third digit had the most whorls (22\%). And finally, the arch pattern which was maximum in the $1^{\text {st }}$ digit (153) with a percentage of $26.4 \%$, was the least common. Invariably the high IQ group showed loops pattern as the predominant type of finger print pattern in all the digits.

\begin{tabular}{|c|c|c|c|c|c|}
\hline High & Thumb & 1st Digit $^{\text {st }}$ & 2nd Digit $^{\text {nd }}$ & 3 $^{\text {rd }}$ Digit & 4 $^{\text {th }}$ Digit \\
\hline No. of Whorls & 94 & 71 & 38 & 128 & 98 \\
\hline No. of Loops & 384 & 356 & 450 & 442 & 468 \\
\hline No. of Arches & 102 & 153 & 92 & 10 & 14 \\
\hline Total & 580 & 580 & 580 & 580 & 580 \\
\hline \multicolumn{2}{|r}{ Table 2 Fingertip Pattern of High Intelligence (Both Hands) } \\
\hline
\end{tabular}

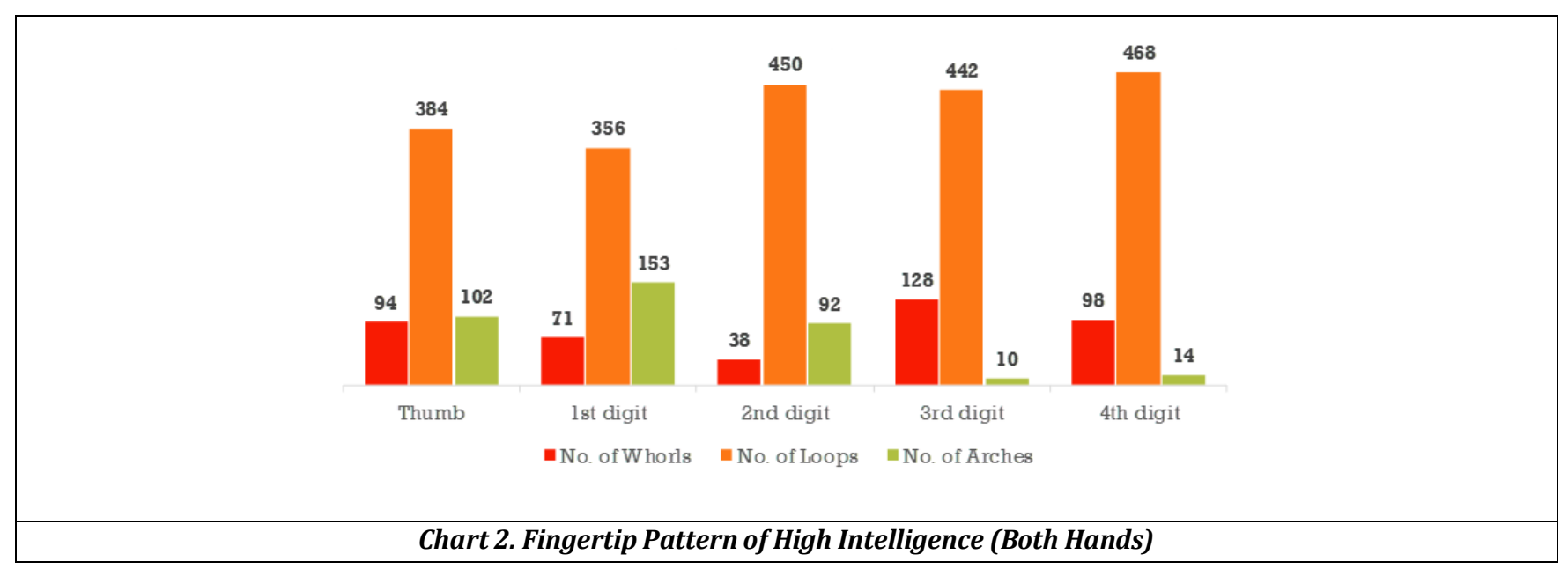

Table 3 depicts the fingertip patterns of the intermediate intelligence group. Chart 3 shows the same. The observations show an increase in number of whorls and arches as compared to the high IQ group. Though the loop pattern was commonly seen, there was a relative increase in number of the whorl pattern. Taking the $1^{\text {st }}$ digit into consideration, the high intelligence quotient group showed $61.4 \%$ of loops, while the intermediate level shows just $54.5 \%$ of loops. The thumb showed the overall highest number of loops with $73.5 \%$, while the $1^{\text {st }}$ digit showed the highest number of arches with $16.8 \%$. The first digit shows a marked increase in arch pattern in the intermediate intelligence group, having about three times as much arches as compared to the other fingers. Finally, most number of whorls were seen in the $1^{\text {st }}$ digit with $28.7 \%$. The $1^{\text {st }}$ digit shows the most deviation from the predominant loop pattern observed in high intelligence group. Both the highest whorl counts, and arch counts were observed in the 1 st digit in the intermediate level. Thus, the first digit was characteristic for the intermediate intelligence group as it showed an increase in whorl and arch patterns of finger print and fall in the loop pattern.

\begin{tabular}{|c|c|c|c|c|c|}
\hline Intermediate & Thumb & 1st Digit & 2 $^{\text {nd }}$ Digit & 3rd Digit $^{\text {th } \text { Digit }}$ \\
\hline No. of Whorls & 184 & 260 & 196 & 254 & 154 \\
\hline No. of Loops & 666 & 494 & 670 & 612 & 712 \\
\hline No. of Arches & 56 & 152 & 40 & 40 & 40 \\
\hline Total & $\mathbf{9 0 6}$ & $\mathbf{9 0 6}$ & $\mathbf{9 0 6}$ & $\mathbf{9 0 6}$ & $\mathbf{9 0 6}$ \\
\hline
\end{tabular}

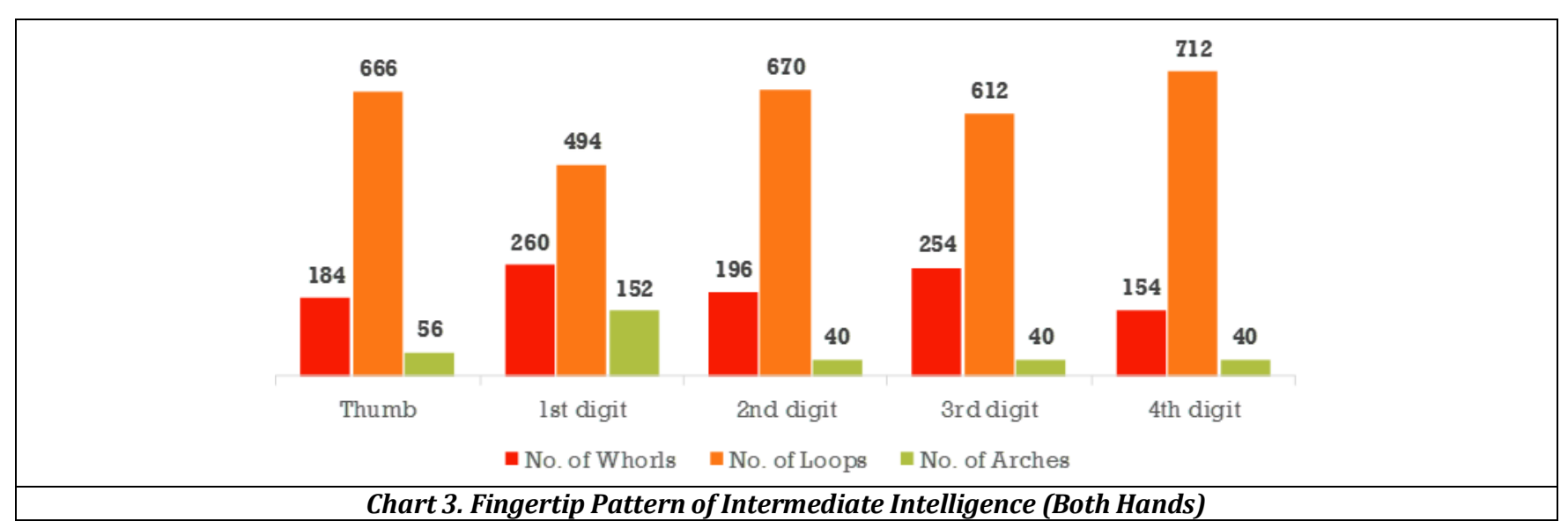


Table 4 depicts the patterns of finger prints in low intelligence quotient group. Chart 4 represents the same. Although loops remain the most predominant pattern, there was a sharp increase in whorls and arches patterns. Similar to the previous group of intermediate IQ level, this group also showed the whorl pattern to be the common in the $1^{\text {st }}$ digit. Another peculiar finding is this is the only digit in the entire study to show more number of whorls than loops. Nearly half the patterns, that is $47.9 \%$, were whorls in the $1^{\text {st }}$ digit. The thumb also showed a higher number of whorl and arch patterns with $36.6 \%$ and $20.6 \%$ respectively. The remaining 3 digits showed the usual predominance of loops. The first digit was characteristic as the whorl pattern is the most common finger print pattern in low IQ group of this digit.

\begin{tabular}{|c|c|c|c|c|c|}
\hline Low & Thumb & 1 $^{\text {st }}$ Digit & 2 $^{\text {nd }}$ Digit & 3 $^{\text {rd }}$ Digit & 4 $^{\text {th }}$ Digit \\
\hline No. of Whorls & 188 & 246 & 86 & 140 & 50 \\
\hline No. of Loops & 220 & 182 & 358 & 360 & 390 \\
\hline No. of Arches & 106 & 86 & 70 & 14 & 74 \\
\hline Total & $\mathbf{5 1 4}$ & $\mathbf{5 1 4}$ & $\mathbf{5 1 4}$ & $\mathbf{5 1 4}$ & $\mathbf{5 1 4}$ \\
\hline \multicolumn{7}{|l}{ Table 4. Fingertip Pattern of Low Intelligence (Both Hands) } \\
\hline
\end{tabular}

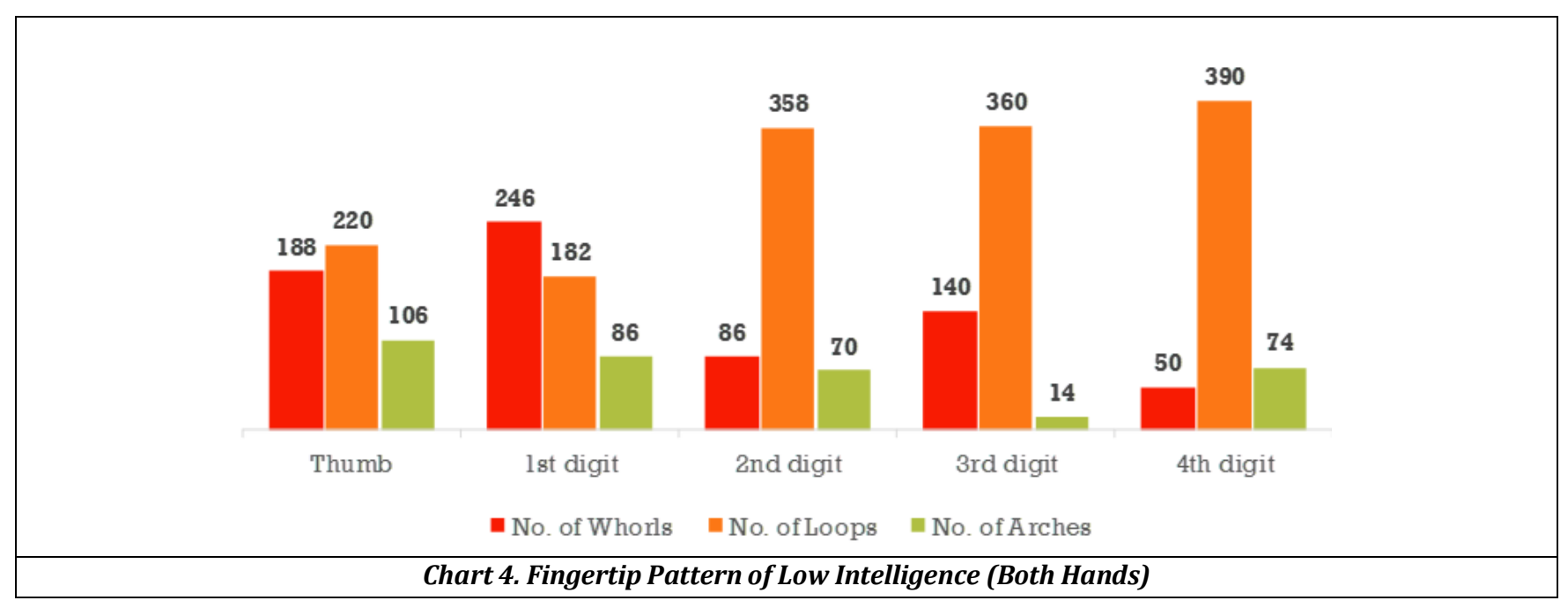

\section{Finger Ridge Counts}

Table 5 shows the average finger ridge counts with their ranges. Chart 5 represents the average as a point on the graph with the ranges represented by a solid line. There is no significant difference in the right and left hands of the finger ridge counts. This accounts to the fact that the patterns present on one hand were almost always symmetrical to the other hand. The absolute finger ridge count increase from a mean of 60.2 to 67.5 from high to low IQ groups. Thus, the absolute finger ridge count was more in low IQ group. The low IQ level shows a significant difference between the total and absolute finger ridge count, indicating a greater preponderance of whorls. Furthermore, the low intelligence level showed the highest spectrum of range. This directly correlates with our previous findings in Table 4, indicating a higher incidence of whorls in students of a lower IQ. The intermediate level shows a less marked difference and the higher IQ shows the least difference in the absolute and total finger ridge count, corresponding with the decreased incidence of whorls as previously indicated in Tables 2 and 1, respectively. The total finger ridge count was maximum in intermediate intelligence group compared to the other groups.

\begin{tabular}{|c|c|c|c|c|c|c|}
\hline & \multicolumn{3}{|c|}{ Right } & \multicolumn{3}{|c|}{ Left } \\
\hline & High $(\mathrm{T}=290)$ & Interm ( $\mathrm{T}=453)$ & Low $(T=257)$ & High $(T=290)$ & Interm ( $\mathrm{T}=453)$ & $\operatorname{Low}(\mathrm{T}=257)$ \\
\hline $\begin{array}{c}\text { Absolute Finger Ridge } \\
\text { Count }\end{array}$ & $\begin{array}{c}60.2 \\
(58-62)\end{array}$ & $\begin{array}{c}65.9 \\
(62-67)\end{array}$ & $\begin{array}{c}67.5 \\
(63-68)\end{array}$ & $\begin{array}{c}60.2 \\
(57-61)\end{array}$ & $\begin{array}{c}65.9 \\
(62-67)\end{array}$ & $\begin{array}{c}67.4 \\
(63-68)\end{array}$ \\
\hline Total Finger Ridge Count & $\begin{array}{c}57 \\
(55-60)\end{array}$ & $\begin{array}{c}63.7 \\
(60-66)\end{array}$ & $\begin{array}{c}51.3 \\
(35-72)\end{array}$ & $\begin{array}{c}57.1 \\
(55-60)\end{array}$ & $\begin{array}{c}63.7 \\
(60-66)\end{array}$ & $\begin{array}{c}51.1 \\
(35-72)\end{array}$ \\
\hline & & Table 5. Avera & e Finger Ridg & unts & & \\
\hline
\end{tabular}




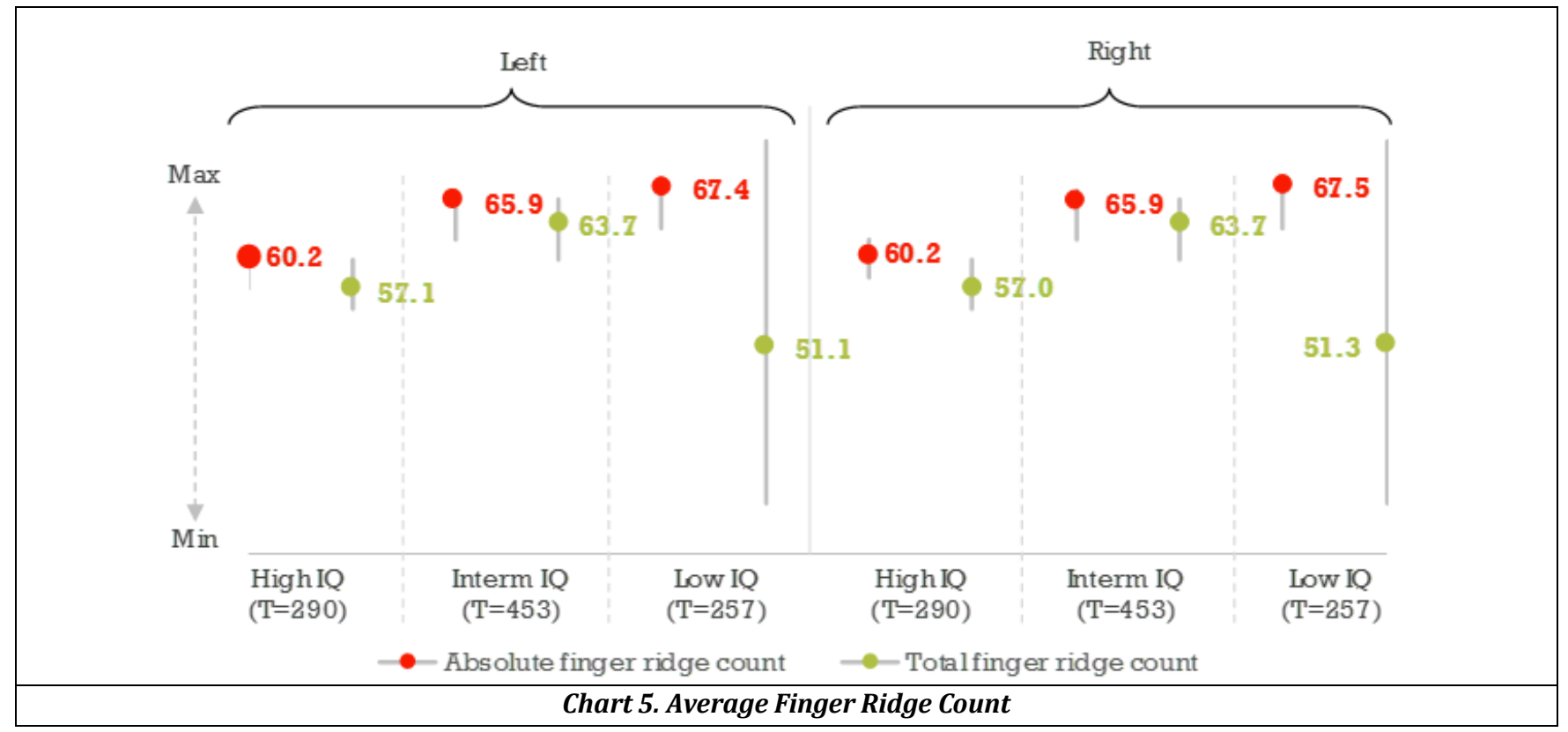

\section{Palmar Ridge Count}

Table 6 shows the average A-B ridge count with the ranges given. Chart 6 indicates the same with the average represented by a point on the graph and the range represented by a solid line. There is a gradual increase in the A-B ridge count as the intelligence quotient decreases thus the A-B ridge count is maximum in the low IQ group. The high intelligence quotient group showed the greatest spectrum of range, while the range was small in intermediate intelligence group.

\begin{tabular}{|c|c|}
\hline & A-B Ridge Count \\
\hline High IQ & $27.3(23-34)$ \\
\hline Intermediate IQ & $30.6(27-34)$ \\
\hline Low IQ & $32.5(27-36)$ \\
\hline \multicolumn{2}{|c|}{ Table 6. Average A-B Ridge Count } \\
\hline
\end{tabular}

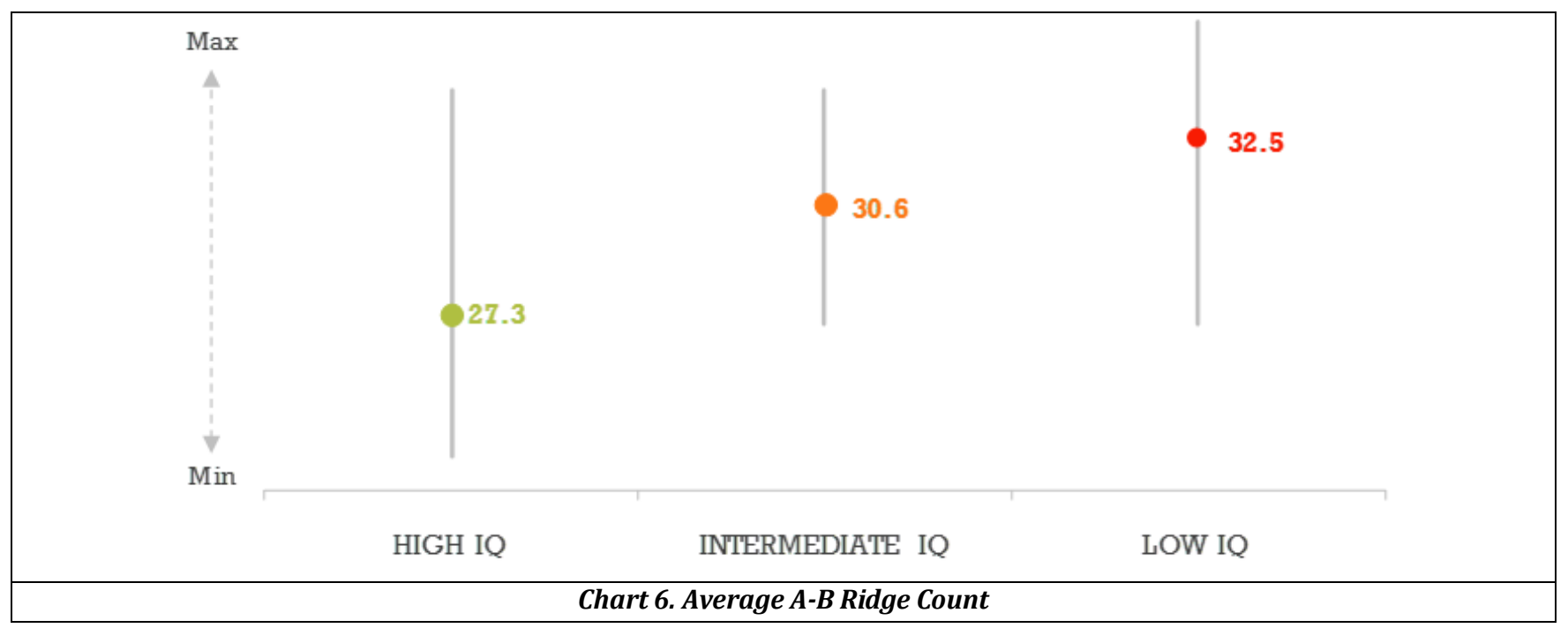

\section{Palmar Angles}

Table 7 shows the average of the 3 main palmar angles that are calculated in the palm. Chart 7 represents the same. The ATD is lowest in the high IQ group and highest in low IQ group. The DAT angle is highest in high IQ group and lowest in intermediate group. Thus, ATD angle was inversely proportional to the intelligence level. The DAT angle is highest in high IQ group and least in intermediate IQ group. Thus, ADT and DAT angles are the highest in high IQ groups and ATD angle was highest in Low IQ group.

\begin{tabular}{|c|c|c|c|}
\hline & ATD Angle & ADT Angle & DAT Angle \\
\hline High IQ & 44 & 78.5 & 55.5 \\
\hline Intermediate IQ & 43 & 79.5 & 47.8 \\
\hline Low IQ & 48.2 & 77.1 & 52.7 \\
\hline \multicolumn{2}{|c|}{ Table 7. Average Palmar Angles } \\
\hline
\end{tabular}




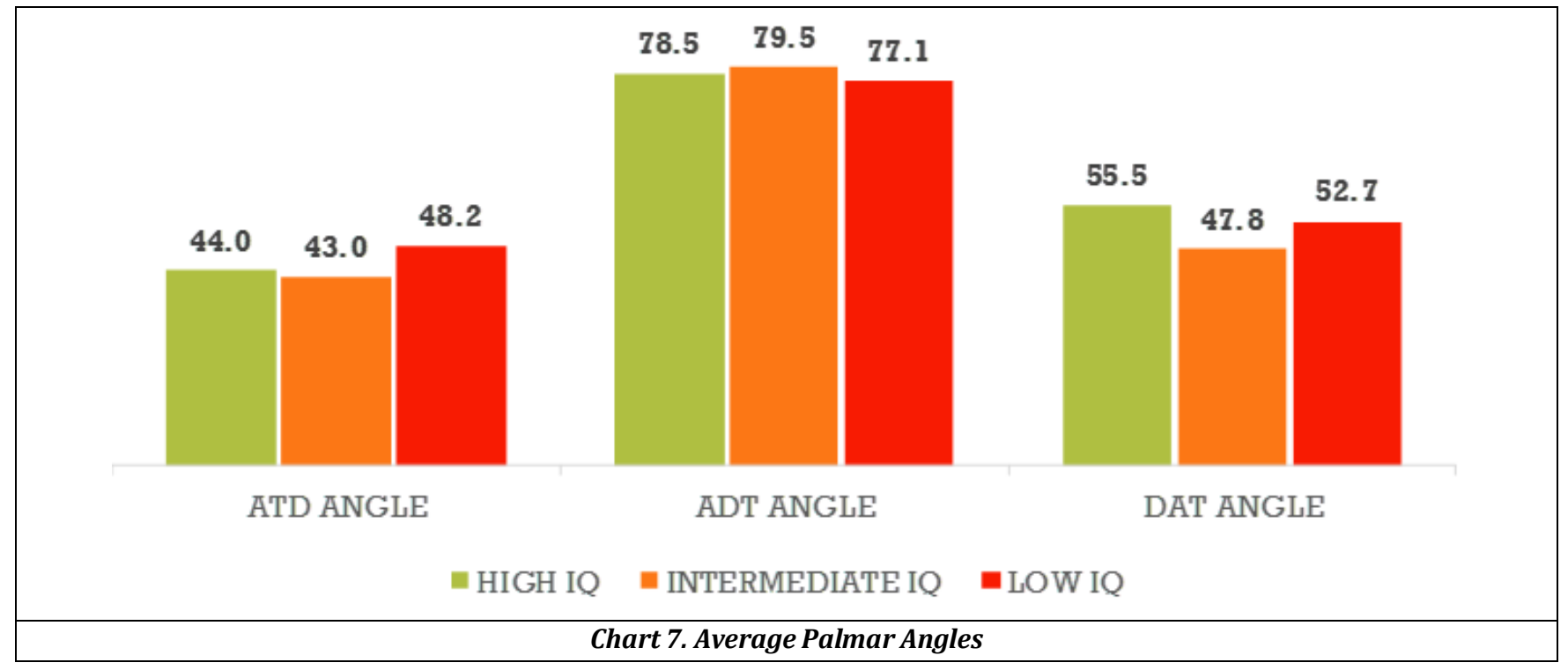

Figures 2, 3, and 4 Show the Hand Print Analysis of The Students from High, Intermediate, and Low Intelligence Levels Respectively

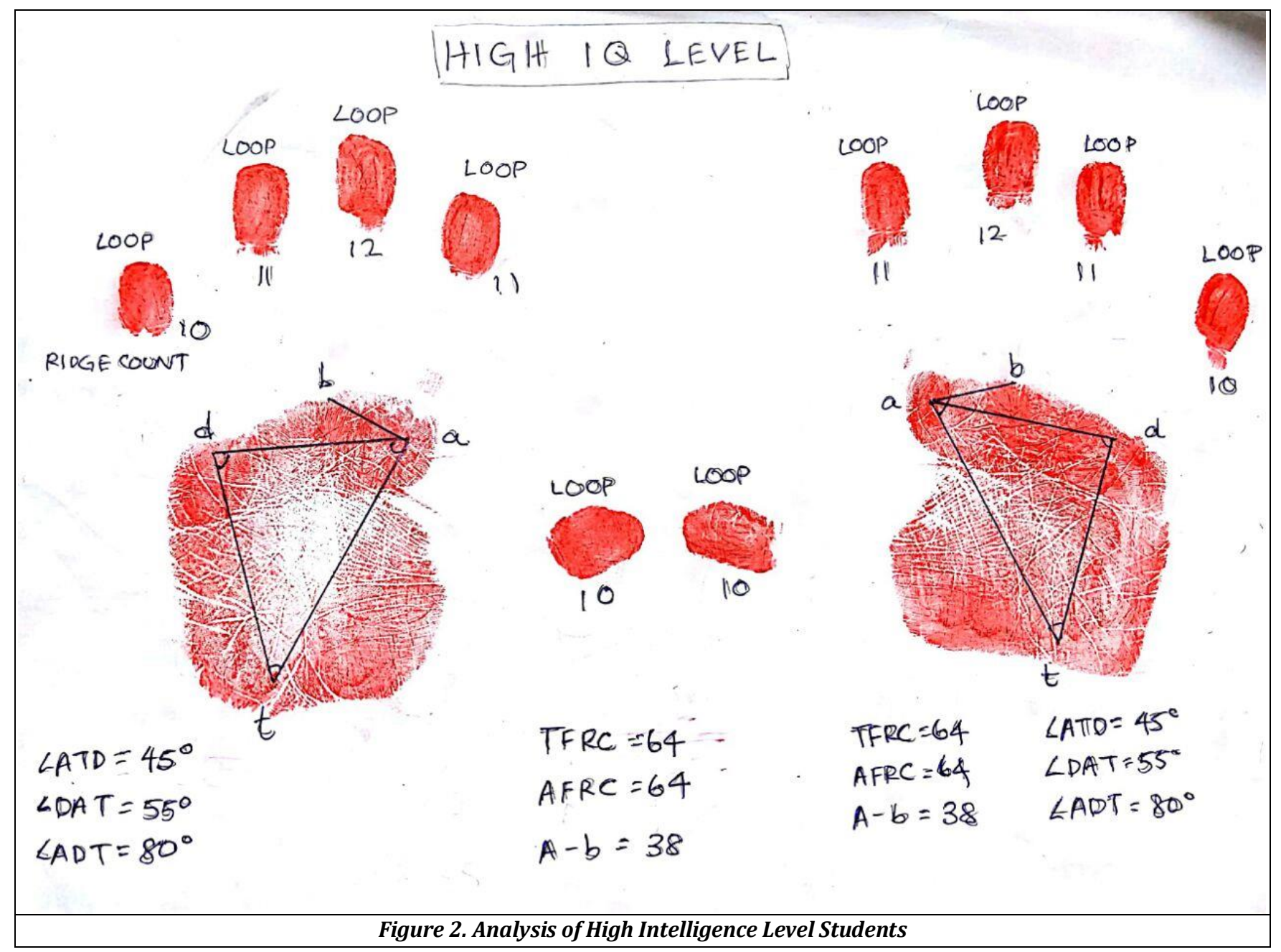



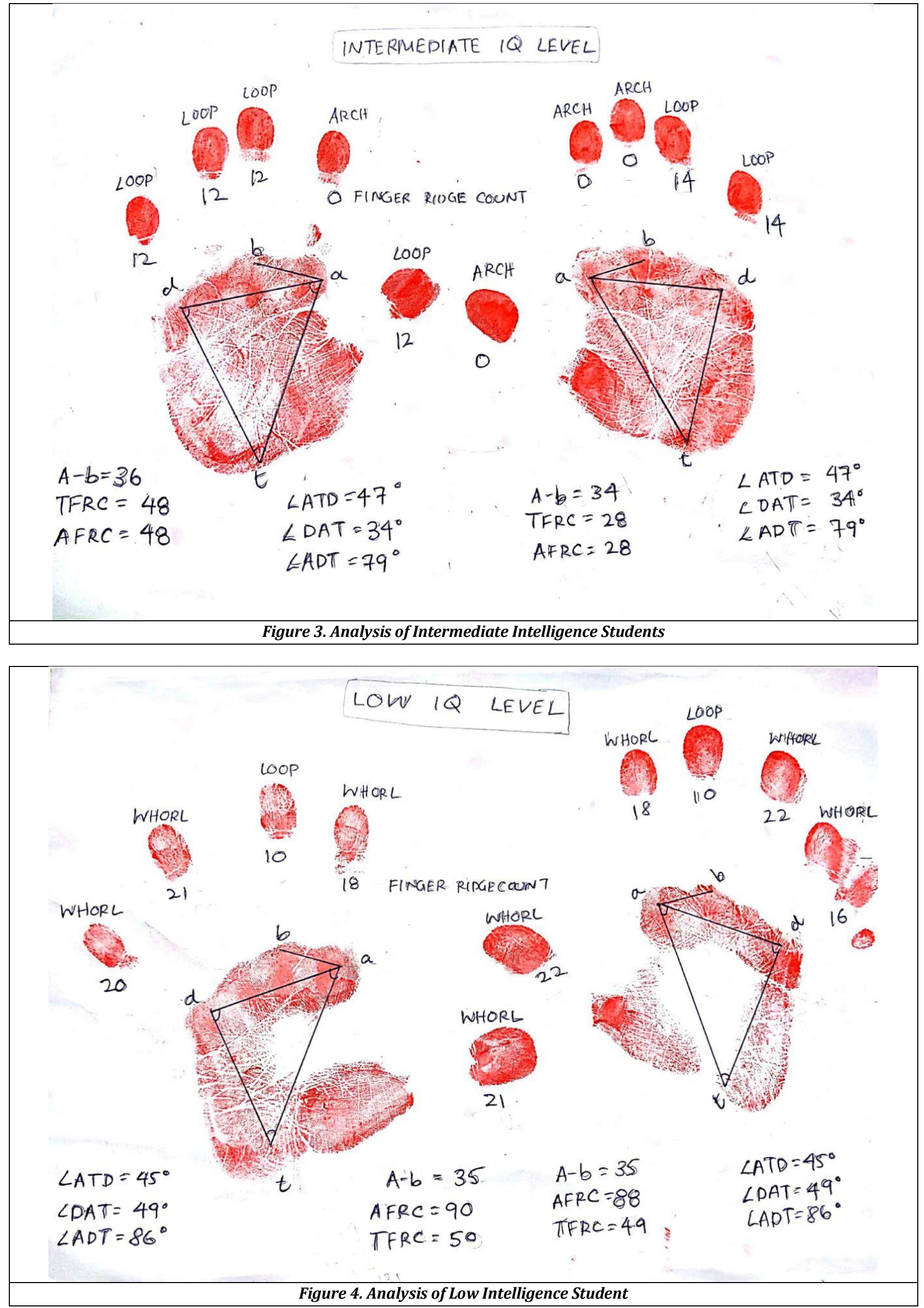


\section{DISCUSSION}

The high intelligence group of students had a predominance of loop patterns. In the medium and low intelligence group the arches and whorls patterns were relatively increased. The thumb and $1^{\text {st }}$ digit especially showed these changes. The average and total finger ridge counts were higher in both left and right hands for low IQ group as compared to intermediate and high IQ group. As the intelligence decreases, the difference between the total and absolute finger ridge counts increases, which also correlates with the increase in the whorl patterns. The A-B ridge count increases from the high to low level of intelligence groups. The analysis of palmar angles showed that the ATD angle was least in low IQ group, the DAT angle was highest in high IQ group and lowest in Intermediate IQ group. The ATD angle was highest in low IQ group and least in intermediate IQ group.

The dermatoglyphic analysis of mentally retarded children was done by Ester Yamuna N and Dhanalakshmi V. On observing the fingertip patterns of the right hand of mentally retarded children, arches were increased in the $1^{\text {st }}$, $3^{\text {rd }}$ and $5^{\text {th }}$ digits whereas $2^{\text {nd }}$ and $4^{\text {th }}$ digit had more loops compared to the controls who had more whorls in the 1 st, $2^{\text {nd }}$, $4^{\text {th }}$ and 5th digits and more loops in the 3rd digits. On observing the fingertip patterns of left hand of mentally retarded children, arches were more common in 1st, 3rd, and 4th digits whereas 2 nd and 5th digit had more loops compared to the control who had more arches in the 2nd digit, more loops in the 1st, 3rd, 4th digit and more whorls in the 2 nd \& 5th digit. When comparing their results with our low intelligence quotient levels, we find that our low IQ levels always had more loops except in the $1^{\text {st }}$ digit, which had more whorls. But the low intelligence group did have the most arch patterns as compared to the other levels of intelligence which does correlate with the study done on mentally retarded children.[9]

A study was conducted by Dr. Lakshmi Kumari et al, on dermatoglyphics and intelligence of medical students and lab technicians with the assumption that the medical students are of higher intelligence due to clearing the competitive exams. A greater number of whorls were seen in most of the students perusing medical lab technician course than among the medical students pursuing MBBS in the same medical college. Our study also showed and increased in the whorl pattern among the lower intelligence group and the loop pattern was prominent among high intelligence group. Arch pattern was seen in the $2^{\text {nd }}$ and $3^{\text {rd }}$ digits of left hand in $10 \%$ of medical students in the above referred study whereas our study showed $15.9 \%$ of arch pattern was seen in the $2^{\text {nd }}$ digit and a mere $1.8 \%$ in the $3^{\text {rd }}$ digit of the high intelligence group. Loop pattern is seen in the $1^{\text {st }}$ digit of both hands of a few medical students and the $2^{\text {nd }}$ and $4^{\text {th }}$ digits of the left hands of a few lab technician students. Among the different type of finger print patterns of the ten fingers whorls and loops were predominant in present study as well as in the above referred study. As expected, the $1^{\text {st }}$ digit of the low IQ group showed predominance of loop pattern in our present study and the referred study.[10]

Mostaf Najali did a study in 2009 to find an association between the fingerprint patterns of the $2^{\text {nd }}$ digit and intelligence quotient of adolescents. Predominant loop pattern on right $2^{\text {nd }}$ digit with high IQ was also seen in this study, which was classically present in our study. Each finger is connected with one brain lobe plus a specific type of intelligence and each type of fingerprint pattern according to this study is connected with the following type of learning-

1. Whorl-Cognitive learning.

2. Ulnar Loop-Affective Learning.

3. Radial Loop- Critical Thinking.

4. Tented Arch- Enthusiastic Learning.

5. Arch-Reflective Learning.

According to this, the high intelligence is concerned with the most affective and critical learning and as the intelligence decreases, the cognitive, reflective, and enthusiastic learning increases.[11]

A study conducted by Adekoya et al to find a relationship between dermatoglyphics and multiple intelligence in students in Nigeria showed whorls and ulnar loop to be the most prominent pattern followed by arch and radial loop. In our present study, the most predominant patterns were loops followed by whorls and then followed by arch. Ulnar loops in the $2^{\text {nd }}$ digit were associated with higher intelligence which was also predominantly seen in our present study among high IQ group. Ulna loop's highest frequency was found on the ring finger (45\%) and arches on the thumb (22\%) for the right hand. Whorls also had the highest frequency (45\%) on the left fingers of females followed by ulna loop (41\%) on the little finger. Arch had its highest frequency on the ring finger (24\%) and radial loop on the ring and little finger (3\% each). Analysis also revealed that whorl and ulna loop patterns were predominant in both males and females that scored above $60 \%$ in each aspect of multiple intelligence test except in musical intelligence where the arch pattern was predominant in males.

The average total ridge count (ATRC) on the right fingers of male students was $40.52 \pm 0.97$ while females were $40.09 \pm$ 1.01. ATRC was $41.44 \pm 0.97$ and $41.30 \pm 0.81$ in male and female students respectively for the left fingers. There was no significant difference between the total ridge count of males and those of females for both hands. However, considering the average total ridge count in each of the intelligence category, ATRC of left fingers in males revealed a significant difference $(P>0.05)$ among the three level of performance in kinesthetic intelligence. High performers (65-100\%) have high ATRC, followed by average (50-64\%) and low (Below $50 \%$ performers respectively. Our study did not differentiate between genders and also did not find significant differences between both hands, so it was not taken into consideration. The total ridge count is similar to those found in the intermediate intelligence levels in our present study.[12]

\section{ACKNOWLEDGEMENT}

Support received by ICMR STS PROJECT to conduct it smoothly.

\section{CONCLUSIONS}

Dermatoglyphics is considered to be a window to a child's personal characteristics and a sensitive indicator of brain function abnormalities. Widespread interest in epidermal ridges is developing in the medical field. In this present study, certain specific patterns were prominent in high, intermediate and low IQ groups which were characteristic of these groups. 
Dermatoglyphics is like a map that leads one to understand his own potential and talents. Everyone inherits innate intelligence from their parents. Everybody's genetic parents have the innate intelligence from their parents. If one's intelligence gets no opportunity to be inspired and further developed, there is no way for one to develop a full range of intelligence, memory, understanding, reasoning, analysis, integration, and application. By analysing dermatoglyphics, we can accurately understand the distribution and number of cells in the left and right brain of the cell, and predict where the potential lies. Although everyone is born with strengths and weaknesses, if they are identified early, we may further develop the strengths and improve our weakness, so that the left and right brain may grow in a more balanced and integrated way.

With more initiatives in the field of dermatoglyphics, it can provide a simple and inexpensive means of determining whether a patient has that particular defect (e.g. mental retardation) or single gene disorder (e.g. Down's Syndrome), both of these conditions do show decreased intelligence quotient. It is especially helpful in those cases were the genetic basis of the disorder is unclear. Dermatoglyphics can be included along with physical examination to provide information regarding certain disorders which are difficult to diagnose and explain. Enormous efforts and interest are needed for dermatoglyphics to be accepted as a diagnostic tool in a variety of mentally deficient states in children and this study is an attempt into considering dermatoglyphics as a diagnostic tool.

\section{REFERENCES}

[1] Kamali MS. Topological formations of palmar dermatoglyphics in Down's syndrome. Int J Phys Anthrop Hum Genet 1985;11:55-60.

[2] Wertheim K. Embryology and morphology of friction ridge skin. Chap- 3. In: McRoberts A, ed. The fingerprint sourcebook. Washington, DC: National Institute of Justice 2011:3-26.

[3] Mulvihill JJ, Smith DW. The genesis of dermatoglyphics. J Pediatr 1969;75(4):579-89.

[4] Boake C. From the Binet-Simon to the WechslerBellevue: tracing the history of intelligence testing. J Clin Exp Neuropsychol 2002;24(3):383-405.

[5] Shahim S. Correlations for Wechsler intelligence scale for children-revised and the Wechsler preschool and primary scale of intelligence for Iranian children. Psychol Rep 1992;70(1):27-30.

[6] Gupta RK, Gupta AK. New, easy and effective method to take dermatoglyphic prints. National Journal of Medical Research 2013;3(1):45-7.

[7] Sridevi NS, Delphine Silvia CR, et al. Palmar dermatoglyphics in carcinoma breast of Indian women. Rom J Morphol Embryol 2010;51(3):547-50.

[8] Oladipo GS, Sapira MK, Ekeke ON, et al. Dermatoglyphics of prostate cancer patients. Current Research Journal of Biological Sciences 2009;1(3):131-4.

[9] Yamuna NE, Dhanalakshmi V. Dermatoglyphics study in children with mental retardation. Int J Anat Res 2017;5(1):3541-46.

[10] Kumari KL, Babu PVSSV, Kumar SV. Dermatoglyphics and its relation to intelligence levels of young students. IOSR Journal of Dental and Medical Sciences 2014;13(5):1-3.

[11] Najafi M. Association between finger patterns of digit II and intelligence quotient level in adolescents. Iran J Pediatr 2009;19(3).277-84.

[12] Adekoya KO, Ahmed RA, Oboh BO, et al. Relationships between dermatoglyphics and multiple intelligence among selected secondary school students in Lagos state, Nigeria. NISEB Journal 2013;13(3\&4):53-60. 